\title{
THE EFFECTS OF SPEECH PRODUCTION AND SPEECH COMPREHENSION ON SIMULATED DRIVING PERFORMANCE
}

\author{
Tate T. Kubose, Kathryn Bock, Gary S. Dell, \\ Susan M. Garnsey, Arthur F. Kramer, Jeffrey Mayhugh \\ Beckman Institute for Advanced Science and Technology \\ University of Illinois, Urbana-Champaign \\ Urbana, Illinois, USA \\ E-mail: kubose@uiuc.edu
}

\begin{abstract}
Summary: We performed two experiments comparing the effects of speech production and speech comprehension on simulated driving performance. In both experiments, participants completed a speech task and a simulated driving task under single- and dual-task conditions, with language materials matched for linguistic complexity. In Experiment 1, concurrent production and comprehension resulted in more variable velocity compared to driving alone. Experiment 2 replicated these effects in a more difficult simulated driving environment, with participants showing larger and more variable headway times when speaking or listening while driving than when just driving. In both experiments, concurrent production yielded better control of lane position relative to single-task performance; concurrent comprehension had little impact on control of lane position. On all other measures, production and comprehension had very similar effects on driving. The results show, in line with previous work, that there are detrimental consequences for driving of concurrent language use. Our findings imply that these detrimental consequences may be roughly the same whether drivers are producing speech or comprehending it.
\end{abstract}

\section{INTRODUCTION}

Recent empirical and epidemiological research has shown that using devices such as wireless phones while driving is associated with greater driving risks and poorer driving performance (e.g., Hancock, Lesch \& Simmons, 2003; LaBerge-Nadeau et al., 2003; Strayer, Drews \& Johnston, 2003). Research also shows that the source of performance decrements seems to lie in the cognitive demands associated with conversation via wireless telephone, rather than in the physical manipulation (e.g., Lamble, et al., 1999; Nunes and Recarte, 2002; Strayer \& Johnston, 2001). The demands associated with the verbal and cognitive requirements of conversation via wireless telephone affect a wide variety of skills and abilities critical to safe driving, such as judging whether one's vehicle can fit through a certain gap (Brown, Tickner, \& Simmonds, 1969) or adapting to changes in the velocity of a leading vehicle (Brookhuis, de Vries, \& de Waard, 1991). Research examining real and simulated driving performance also found that concurrent verbal tasks result in more glances away from the road (Jenness, et al., 2002), increased reaction time to braking events (Irwin, Fitzgerald, \& Berg, 2000), increased subjective mental workload (Haigney, Taylor, \& Westerman, 2000; Waugh, et al., 2000), and a smaller window of gaze, with glances more concentrated towards the center of the field of vision and reduced glances to side mirrors and speedometer (Recarte \& Nunes, 2000). 
With the abundant evidence that verbal tasks interfere with driving performance and impair mental and perceptual processes critical to the driving task, our goal was to explore more specifically what aspects of speech are most demanding and thus most likely to cause interference. More specifically, the goal of our study was to examine the effects of speech production (talking) and speech comprehension (listening and understanding) on simulated driving performance. Unlike the speech tasks used in most previous studies on concurrent speech and driving, our dual-task paradigm and yoked design allowed comparison of the demands of speech production and speech comprehension separately. Mainstream theories of language processing predict that if the conceptual demands of comprehension and production are equated, the costs of concurrently comprehending or producing while driving will be equal (see Bock \& Kroch, 1989; Fodor, 1983). Other theories predict additional effects associated with production (due to the additional articulation it requires) (see Benedict, 1979; Clark \& Malt, 1984).

In order to examine the effects of speech production and speech comprehension on driving performance, we used a dual-task paradigm with simulated driving as the primary task and a speech production or speech comprehension task as the secondary task. The secondary speech task involved producing or comprehending statements about the spatial relationships between pairs of buildings on the university campus where the experiments were conducted. In the speech production task, participants were cued to produce two-clause statements about the buildings, such as "Lincoln Hall is North of Gregory Hall and Altgeld Hall is North of the Henry Administration Building." The speech comprehension task used recordings of the actual utterances generated during the production experiment. The participants listened to these utterances and had to verify whether each clause of the utterance was true. In this way, the production and comprehension tasks were closely matched. The produced and comprehended sentences were identical. The same knowledge sources were called on, and both tasks required participants to deal with exactly two building pairs. This allowed us to compare speaking and understanding under conditions that ensured similar cognitive processes, processes which are shared by production and comprehension.

Experiment 1 examined the effects of speech production and speech comprehension on continuous measures of velocity and lane maintenance. In Experiment 2, a replication and extension of the first experiment, driving performance was assessed in terms of headway maintenance as well as lane maintenance. Based on past literature showing the negative effects of concurrent verbal tasks on driving performance, we predicted that performance on our driving measures would be worse under dual-task conditions than single-task conditions. More specifically, in Experiment 1, variability in velocity and lane position should be greater when driving while carrying out a speech task than when driving alone. In addition to the general effects associated with the speech production and comprehension tasks, we predicted that the additional task of articulation required in speech production would result in worse driving performance for the participants completing the speech production task than the speech comprehension task. 


\section{METHOD}

\section{Participants}

There were 48 participants in each experiment; all were native-English speakers from the University of Illinois. Twenty-seven males and twenty-one females participated in Experiment 1, averaging 21.73 years of age $(\mathrm{SD}=2.28)$; they had an average of 5.13 years of driving experience $(\mathrm{SD}=2.33)$ and drove approximately 6,300 miles per year on average. Experiment 2 included 28 females and 20 males, average age of 20.2 years, $\mathrm{SD}=1.88$, with 3.96 years of driving experience, driving approximately 6,000 miles per year. All participants were paid $\$ 12$ for their participation, which lasted slightly more than an hour.

\section{Materials}

Speech tasks. On each trial in the speech production task, participants (speakers) heard the names of two buildings on the University of Illinois campus, followed by a map direction (North, South, East, or West) after a five-second delay. For each building presented, the task required the speakers to use their existing knowledge of the campus to identify and name a neighboring building that was located in the specified direction. They then had to produce the name of that building. So if given Building A and Building B and the direction North, the speaker was directed to respond "Building X is North of Building A, and Building Y is North of Building B." Each trial lasted approximately thirty-three seconds, resulting in thirteen complete trials in the single-task Speech-Only condition and twenty-seven complete trials in the dual-task DriveProduction (Drive-Speech) condition. During the speech comprehension task, participants (comprehenders) heard the recorded answers given by the speakers in the speech production condition. The comprehenders' task was to verify whether the two statements given about the relationships between pairs of campus buildings were correct. That is, comprehenders judged the accuracy of the statements given by speakers in the speech production condition. The stimuli were created from the audio files generated by the speakers. On each trial of the comprehension task, participants first heard an audio file warning them that the trial was beginning (the readyprompt). They then heard the twenty-second response from a trial in the speech production task. After the entire response was heard, a tone sounded, prompting the comprehenders to respond via two buttons (indicating 'correct' or 'incorrect') mounted on the steering wheel. Each trial lasted approximately twenty-eight seconds, including a ready-prompt, the twenty-second response from the speech production trial, and the signal for the participant to respond, in that order.

Driving tasks. In both experiments, all three conditions (Drive-Only, Speech-Only, and DriveSpeech) took place on a simulated, straight, two-lane rural highway with no intersections or turns. There was occasional oncoming traffic. In Experiment 1, there was no traffic in the participant's lane, and they were instructed to stay as close to 55 miles per hour (24.6 meters per second) as possible while driving. In Experiment 2, there was a single lead vehicle in front of the participants' vehicle, and they were instructed to maintain a two-second headway behind the lead vehicle. In both experiments, participants were also instructed to stay as close to the center of their lane as possible. In order to increase the difficulty of the driving task, simulated gusts of wind either slowed the participant's vehicle, or pushed it left or right. During the Drive-Only condition, participants drove for approximately eight minutes along the highway. During the 
Speech-Only condition, participants parked on the side of the road and performed the speech production or speech comprehension task for approximately eight minutes. In the Drive-Speech condition, participants drove for approximately fifteen and a half minutes while also performing the speech production or speech comprehension task. In each condition that involved driving, data collection did not begin for thirty seconds, to allow participants to advance to fifty-five miles per hour.

For half of the comprehenders, the Drive-Only condition was replaced with the Drive-Button condition. Because the comprehenders used the steering-wheel buttons to respond during the Drive-Speech condition but not in the Drive-Only condition, the possibility exists that driving performance may differ as a result of the button-pressing, with or without any differences due to the speech comprehension task. The Drive-Button condition required comprehenders to press the steering-wheel buttons in response to two tones played every twenty seconds through either the left or right car speakers. This was done to closely approximate the button-pressing required in the speech comprehension task, yet lacked the comprehension component. Ultimately, buttonpressing did not result in any significant differences in driving, and thus the Drive-Only and Drive-Button conditions were collapsed.

\section{Procedure}

All participants completed a test/training session that ensured that they knew all of the building names and locations required to complete the speech tasks. Participants then received practice driving the vehicle in the experimental environment, followed by five minutes of practice on their speech task (either the production or comprehension task). Driving practice in Experiment 1 was three minutes long, and they were given the same instructions as for the experimental driving conditions. Driving practice in Experiment 2 was six minutes long, and participants were instructed regarding what a two-second headway was, and were also given audio feedback regarding their headway during the practice session. Before the experimental sessions began, participants were instructed to obey traffic laws and respond to traffic events as they normally would. They were also reminded of the nature of the trials in the assigned speech task. Before the Drive-Speech stage, participants were told to complete the speech task as well as they could, but not to let it compromise driving safety. The order of the three conditions, Drive-Only, SpeechOnly, and Drive-Speech, was counterbalanced across participants.

\section{RESULTS}

\section{Speech Task Performance}

In both experiments, percent accuracy did not differ across Speech-Only and Drive-Speech for either speech task (production or comprehension). Performance was generally good, approximately $85 \%$ or greater in all conditions, with no differences across conditions. Thus, concurrent driving did not affect the accuracy of performance on the speech tasks.

\section{Driving Performance}

Measures. The primary measures of driving performance were the participants' average mean and standard deviation of velocity (Experiment 1), headway time (Experiment 2) and lane 
position (both experiments). Velocity was measured in meters per second. Headway time was measured in seconds. Lane position was measured in meters, relative to the center of the participant's lane. Positive values indicate deviation to the right of the center of the lane, and negative values indicate deviation to the left. Driving performance was measured at $60 \mathrm{~Hz}$; that is, the value of each measure was recorded 60 times per second, and the resulting data were analyzed for the entire condition. The first 30 seconds of driving were not included so as to allow the participant to accelerate to 55 miles per hour (24.6 meters per second); this served to reduce any variance in velocity due to differences in preferred rate of acceleration. Thus, the total duration of driving data analyzed was 7.5 minutes for the Drive-Only condition and 15 minutes for the Drive-Speech condition.

Experiment 1. Across speech task conditions, velocity was more variable under dual-task conditions $(M=1.24 \mathrm{~m} / \mathrm{s}, S D=.43)$ than in single-task conditions $(M=1.07 \mathrm{~m} / \mathrm{s}, S D=.53), \mathrm{F}(1$, $46)=14.69, \mathrm{p}<.05, M S E=.049$. In addition, Production participants $(25.12 \mathrm{~m} / \mathrm{s}, S D=.97)$ drove faster on average than Comprehension participants $(24.61 \mathrm{~m} / \mathrm{s}, S D=.91), \mathrm{F}(1,46)=4.52$, $\mathrm{p}<.05, M S E=1.395$. An interaction between task-load and speech task $(\mathrm{F}(1,46)=4.11, \mathrm{p}<$ $.05, \underline{\mathrm{MSE}}=.017)$ revealed that Production (but not Comprehension) participants were also less variable in lane position when driving and speaking $(M=.38, S D=.07)$ than when driving without speaking $(M=.42, S D=.10), \mathrm{t}(23)=3.11, \mathrm{p}<.05$.

Experiment 2. Across speech task conditions, headway time under dual-task conditions was both larger on average $(\mathrm{F}(1,46)=8.29, \mathrm{p}<.05, M S E=.074 ; M=2.48$ seconds, $S D=.56$ and $M=$ $2.32, S D=.506$ for dual-task and single-task conditions, respectively) and more variable ( $\mathrm{F}(1$, $46)=16.65, \mathrm{p}<.05, M S E=.008 ; M=.53, S D=.26$ and $M=.45, S D=.24$ for dual-task and single-task conditions, respectively) than under single-task conditions. Also, replicating the pattern of results in Experiment 1, there was again an interaction between task-load and speech task $(\mathrm{F}(1,46)=4.42, \mathrm{p}<.05, \underline{\mathrm{MSE}}=.008)$ that revealed that Production (but not Comprehension) participants were less variable in lane position when performing in the dual-task condition $(M=.31, S D=.09)$ than in the single-task condition $(M=.34, S D=.10), t(23)=$ $3.347, \mathrm{p}<.05$.

\section{DISCUSSION}

Our experiments showed that speech production and speech comprehension, for the most part, had similar (detrimental) effects on driving performance. This similarity implies that it is the components and demands that are shared by both speech production and speech comprehension (namely the conceptual processes rather than the translation processes) that are the main contributors to the interference upon driving performance. This interpretation is similar to and extends the interpretation of Nunes and Recarte's recent work (e.g., Nunes \& Recarte, 2002; Recarte \& Nunes, 2000). They argue that it is the cognitive demands of the secondary tasks that cause the most interference on driving performance, rather than demands specific to communication via phone.

We also found that concurrent speech production (but not speech comprehension) resulted in less variability in lane position than when driving alone; we found this effect in both experiments. We interpreted this as evidence that drivers are able to prioritize allocation of mental resources to those aspects of driving that are more critical to safety. That is, given the increased demands 
brought forth by the speech production task, drivers can no longer devote all of their resources to the driving task; as a result, some aspects of driving suffer. In our driving scenarios, the safe choice was to continue monitoring lane position at the expense of velocity or headway control (after also increasing headway distance in Experiment 2). This finding is similar to and extends Alm and Nilsson's (1994) explanation of their findings. They found that driving performance on an easy track suffered with concurrent performance of a phone task, but that performance on a harder track did not show similar decrements in performance. Their explanation of these results highlighted the driver's recognition of the more demanding driving task in the harder track, and subsequent allocation of more resources aimed at performing the driving task rather than the phone task (see also Laberge, Scialfa, White, and Caird, in press).

The results of our experiments support the findings of previous literature, both the overall tendency for secondary speech tasks to interfere with driving performance, and the ability of drivers to adapt to their driving environments in a compensatory manner when under difficult dual-task conditions. We plan to further examine the similarities and differences between the effects of speech production and speech comprehension on driving performance by exploring additional speech tasks and driving environments. More specifically, we plan to develop speech tasks that are more naturalistic (such as a conversation task), thus improving our ability to generalize our findings to real-life situations.

\section{ACKNOWLEDGMENTS}

We are grateful to Pierre Wiltzius and the Beckman Institute, and Ko Kurokawa and General Motors for providing support. We are also grateful to the National Institutes of Health (grant numbers T32-MH18990 and R01-MH66089), and the National Science Foundation (grant number BCS-0214270) for their generous support. We thank Hank Kaczmarski, Braden Kowitz, Camille Goudeseune, Jim Farrar, and Debbie Carrier for helping keep the simulator laboratory running smoothly. We would also like to thank Jill Barr, Valerie Brisky, Natalie Hall, Christopher Johnson, Jeff Nelson, Ankur Patel, Erik Pedersen, Seth Redenbo, Brian Roland, and Aaron Yao for their help with data collection.

\section{REFERENCES}

Alm, H. \& Nilsson, L. (1994). Changes in driver behaviour as a function of handsfree mobile phones-A simulator study. Accident Analysis and Prevention, 26, 441-451.

Benedict, H. (1979). Early lexical development: Comprehension and production. Journal of Child Language, 6, 183-200.

Bock, J. K., \& Kroch, A. S. (1989). The isolability of syntactic processing. In G. N. Carlson \& M. K. Tanenhaus (Eds.), Linguistic structure in language processing (pp. 157-196). Dordrecht: Kluwer.

Brookhuis, K. A., de Vries, G., de Waard, D. (1991). The effects of mobile telephoning on driving performance. Accident Analysis and Prevention, 23, 309-316.

Brown, I. D., Tickner, A. H., Simmonds, D. C. V. (1969). Interference between concurrent tasks of driving and telephoning. Journal of Applied Psychology, 53, 419-424. 
Clark, H. H. \& Malt, B. C. (1984). Psychological constraints on language: A commentary on Bresnan and Kaplan and on Givón. In W. Kintsch, J. R. Miller \& P. G. Polson (Eds.), Method and tactics in cognitive science (pp. 191-214). Hillsdale, NJ: Erlbaum.

Fodor, J. A. (1983). The modularity of mind. Cambridge, MA: MIT Press.

Haigney, D. E., Taylor, R. G., \& Westerman, S. J. (2000). Concurrent mobile (cellular) phone use and driving performance: task demand characteristics and compensatory processes. Transportation Research Part F, 113-121.

Hancock, P. A., Lesch, M., \& Simmons, L. (2003). The distraction effects of phone use during a crucial driving maneuver. Accident Analysis and Prevention, 35, 501-514.

Irwin, M., Fitzgerald, C., \& Berg, W. P. (2000). Effect of the intensity of wireless telephone conversations on reaction time in a braking response. Perceptual and Motor Skills, 90, 11301134.

Jenness, J. W., Lattanzio, R. J., O’Toole, M., Taylor, N., \& Pax, C. (2002). Effects of manual versus voice-activated dialing during simulated driving. Perceptual and Motor Skills, 94, 363379.

Laberge, J., Scialfa, C., White, C., \& Caird, J. (In press). The effect of passenger and cellular phone conversations on driver distraction. Transportation Research Record.

Laberge-Nadeau, C., Maag, U., Bellavance, F., Lapierre, S., Desjardins, D., Messier, S., \& Saïdi, A. (2003). Wireless telephones and the risk of road crashes. Accident Analysis and Prevention, 35, 649-660.

Lamble, D., Kauranen, T., Laasko, M., \& Summala, H. (1999). Cognitive load and detection thresholds in car following situations: Safety implications for using mobile (cellular) telephones while driving. Accident Analysis and Prevention, 31, 617-623.

Nunes, L. M. \& Recarte, M. A. (2002). Cognitive demands of hands-free-phone conversation while driving. Transportation Research Part F 5, 133-144.

Recarte, M. A. \& Nunes, L. M. (2000). Effects of verbal and spatial-imagery tasks on fixations while driving. Journal of Experimental Psychology: Applied, 6, 31-43.

Strayer, D. L., Drews, F. A., \& Johnston, W. A. (2003). Cellphone-induced failures of visual attention during simulated driving. Journal of Experimental Psychology: Applied, 9, 23-32.

Strayer, D. L. \& Johnston, W. A. (2001). Driven to distraction: Dual-task studies of simulated driving and conversing on a cellular telephone. Psychological Science, 12, 462-466.

Waugh, J. D., Glumm, M. M., Kilduff, P. W., Tauson, R. A., Smyth, C. C., \& Pillalamarri, R. S. (2000). Cognitive workload while driving and talking on a cellular phone or to a passenger. Proceedings of the IEA 2000/HFES 2000 Congress, 6-276 - 6-279. 